\title{
Carbon sequestration due to the abandonment of agriculture in the former USSR since 1990
}

\author{
Nicolas Vuichard, ${ }^{1,2}$ Philippe Ciais, ${ }^{3}$ Luca Belelli, ${ }^{1}$ Pascale Smith, ${ }^{3}$ \\ and Riccardo Valentini ${ }^{1}$
}

Received 13 March 2008; revised 23 September 2008; accepted 9 October 2008; published 23 December 2008.

[1] The end of the Soviet Union and the collapse of its agricultural structures in the early 1990s has induced the abandonment of a large croplands area, which have been recovered by herbaceous plants. This widespread unintended and abrupt land use change took place over $200,000 \mathrm{~km}^{2}$, a large enough scale to impact the continental and global carbon budgets. The goal of this study is to estimate the net biome productivity (NBP) of the abandoned croplands and to assess the soil $\mathrm{C}$ storage dynamics due to recent land conversion. The soil $\mathrm{C}$ balance and its input (net primary productivity) and output (heterotrophic respiration) fluxes is simulated in a spatially explicit manner with the process-driven natural vegetation/crop model ORCHIDEE-STICS prescribed with successive area changes of abandoned croplands during the 1990s.* We estimate that regional agricultural abandonment is responsible of a cumulated carbon sink over 19912000 of $373 \mathrm{gC} \mathrm{m}^{-2}$, or $64 \mathrm{TgC}$ over the domain considered, which defines a mean annual $\mathrm{C}$ sink of $46.7 \mathrm{~g} \mathrm{C} \mathrm{m}^{-2} \mathrm{a}^{-1}$. Agricultural practices during the former cultivation phase determine a legacy on the $\mathrm{C}$ sink following abandonment, which impacts by $+37 \%$ to $-25 \%$ according to the practice considered (no tillage, no fertilization, and export of some crop residues). We conclude that futures studies of this regional change in the $\mathrm{C}$ cycle should better consider management information in order to refine the NBP estimate.

Citation: Vuichard, N., P. Ciais, L. Belelli, P. Smith, and R. Valentini (2008), Carbon sequestration due to the abandonment of agriculture in the former USSR since 1990, Global Biogeochem. Cycles, 22, GB4018, doi:10.1029/2008GB003212.

\section{Introduction}

[2] The collapse of the Soviet Union and its agricultural structures in the early 1990s has caused the abandonment of a large croplands area, of up to 20 millions of hectares [Food and Agriculture Organization, 2004]. On the abandoned fields, grass-dominated vegetation has recovered the land. Thus, a widespread unintended land use change took place in the 1990s, with important implications on regional details of the $\mathrm{C}$ cycle. In their review of the literature of soil carbon increases following a land use reversal to natural vegetation, Post and Kwon [2000] underline that the "accumulation process essentially reverses some of the effects responsible for soil organic carbon losses from when the land was converted from perennial vegetation." They assess an average $\mathrm{C}$ sink for natural grassland reestablishment of $33.8 \mathrm{~g} \mathrm{C} \mathrm{m}^{-2} \mathrm{a}^{-1}$, where a is years, with a large uncertainty according to the productivity of the recovering vegetation, physical and biological conditions in the soil, and past

\footnotetext{
${ }^{1}$ Department of Forest Resources and Environment, University of Tuscia, Viterbo, Italy.

${ }^{2}$ Centre International de Recherche sur l'Environnement et le Développement, EHESS, CNRS, Nogent sur Marne, France.

${ }^{3}$ Laboratoire des Sciences du Climat et de l'Environnement, IPSL, CEA, CNRS, Gif-sur-Yvette, France.

Copyright 2008 by the American Geophysical Union. 0886-6236/08/2008GB003212\$12.00
}

history of SOM inputs and its physical disturbance. In fact, land use change plays a major role on the global terrestrial carbon budget (or net biome productivity (NBP)). In their study that aims to project the changes in soil carbon of European grasslands over 1990-2080, Smith et al. [2005] showed that while climate change will be a driver of change in soil carbon over the 21 st century, changes in technology and land use are projected to have very significant effects. In addition, Pielke [2005] noticed that the role of land use and land cover change and variability in altering regional temperature, precipitation, albedo and other components of the surface energy budget has been mostly ignored. Quoting the study of Feddema et al. [2005], he concluded that land use and land cover modifications will continue to alter the regional and global climate system in the 21 st century, with these changes acting as a climate-forcing agent.

[3] The goal of this study is to estimate the Net Biome Productivity (NBP) of recent converted croplands of former USSR, as caused by agricultural abandonment in the early 1990s. NBP is estimated using a spatially explicit modeling framework on the basis of the process-driven ecosystem model ORCHIDEE-STICS [Krinner et al., 2005].* That model can handle both grass-dominated vegetation and crops. It has already been recently reparameterized and

\footnotetext{
${ }^{*}$ The sentences are correct here. The article as originally published appears online.
} 

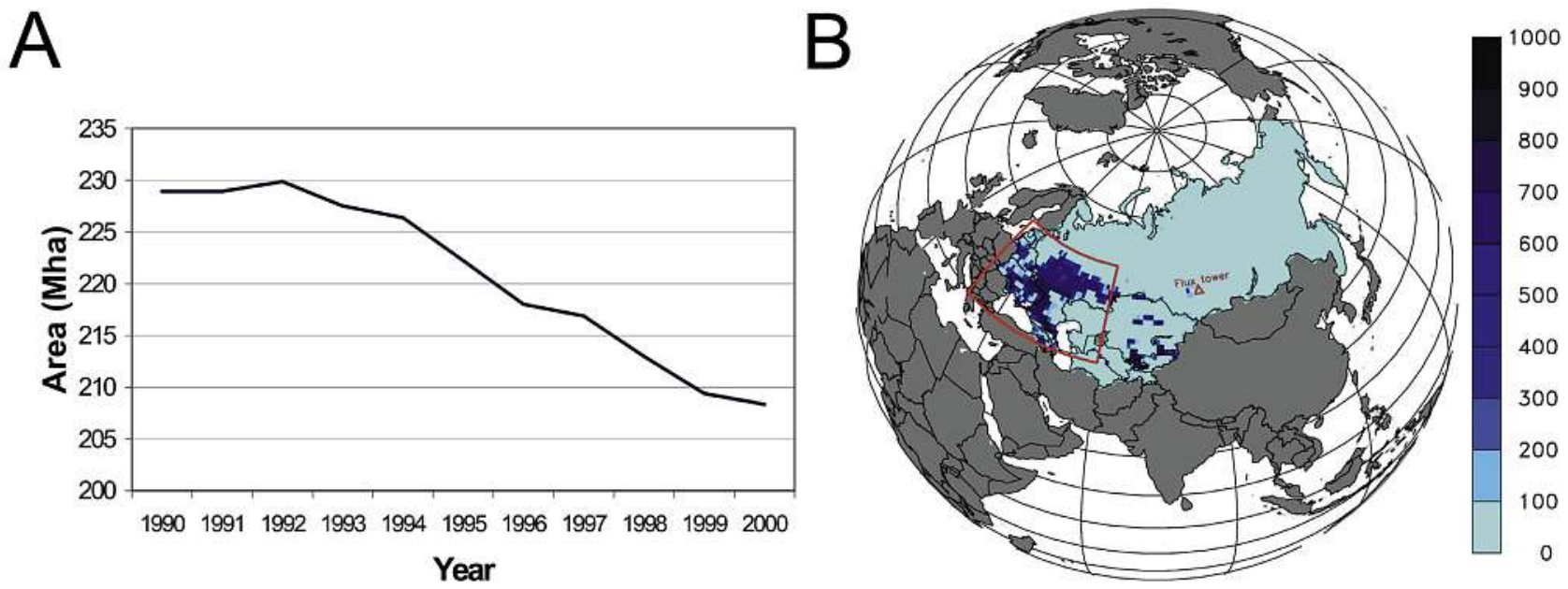

Figure 1. (a) Decreasing cropland area in the former USSR as reported by the FAO agricultural global database during the 1990s. (b) Spatial distribution of croplands abandonment (in $\mathrm{km}^{2}$ ) from 1991 to 2000 as reported by Hurtt et al. [2006] at a $1^{\circ}$ by $1^{\circ}$ resolution. The red domain is the one modeled in this study. The red triangle symbolizes the location of the flux tower with which the model's C3 grass PFT has been improved.

improved for southern Siberian steppes (N. Vuichard et al., On the ability of the ORCHIDEE global vegetation model to simulate carbon and water fluxes of a Southern Siberian Steppe, submitted to Rangeland Ecology and Management, 2008). Here we will also modify the crop module to better reproduce Soviet agriculture cereals yields in that region. ORCHIDEE-STICS was prescribed with successive decreasing cropland area changes throughout the 1990s. In the following, we first describe the studied area and its ecosystems (section 2.1), then the land use change scenarios (section 2.2) and the ORCHIDEE-STICS model (section 2.3). In a second step, we present the model results in term of net primary productivity (NPP) and NBP trajectories of the recovering grass-dominated vegetation, and compare these $\mathrm{C}$ fluxes to those of undisturbed croplands. The impact of former management practices during the cultivation phase on the subsequent $\mathrm{C}$ sinks after abandonment is estimated. This leads to formulating recommendations for taking future measurement studies to further reduce uncertainties.

\section{Methods}

\subsection{Area of Interest}

[4] According to the Food and Agriculture Organization [2004], it is more than 20 millions of hectares of permanent crops and arable lands that have been abandoned in the former USSR territory between 1993 and 2000 (Figure 1a). The total area of abandoned cropland over the entire former USSR is reported on a yearly time step by the Food and Agriculture Organization [2004] agricultural statistics. The shrinking total cropland area is distributed using the spatial land use pattern calculated by the global modeling study of Hurtt et al. [2006] which accounts for the marginality of land in the abandonment process. Hurtt et al. [2006] suggest that $80 \%$ of the USSR cultivated lands abandoned during the 1990 s were located within a region bounded by $40^{\circ}$ and $60^{\circ} \mathrm{N}$ in latitude and $20^{\circ}$ and $60^{\circ} \mathrm{E}$ in longitude (Figure $1 \mathrm{~b}$ ), the last $20 \%$ being spread over the rest of the former USSR territory. Thus, for computer time limitation, our analysis is focused on the region within $80 \%$ of the abandonment took place. According to Hurtt et al. [2006], in 1950, 38\% of the land in this region was covered with crops, $24 \%$ with pastures, $31 \%$ with primary vegetation, and $7 \%$ only of secondary vegetation (i.e., ecosystems that have experienced some amount of land use and are in a state of recovery). Within the studied region, primary vegetation types vary with the bioclimatic zones across a N-NW gradient. From South to North, they are grass vegetation for the steppe zone, grass/tree mixed vegetation for the forest steppe zone and trees for the forest and taiga zones.

\subsection{Management and Land use Change Scenarios}

[5] Over the studied domain, we developed a land use change scenario over the 20th century. The processes of transformation of abandoned lands can be described as an ecosystem succession, during which a vegetation community is replaced by another, gradually. Succession often progresses to a stable terminal community related to its bioclimatic zone. However, early stage of ecosystem succession is mainly dominated by colonization of herbaceous plants. In this respect, the aim of our study being to assess the $\mathrm{C}$ balance of abandoned lands in the first decade after conversion, it is reasonable to model the vegetation after abandonment by the Natural $\mathrm{C} 3$ grass plant functional type (PFT) of the ORCHIDEE global vegetation model [Krinner et al., 2005] even if the land may also be covered by lichens, shrubs and young trees according to the bioclimatic zone considered. For this type of vegetation, ORCHIDEE has already been reparameterized and improved against eddy covariance measurements at a steppe site in southern Siberia (Vuichard et al., submitted manuscript, 2008). Crops are simulated by the ORCHIDEE-STICS submodule 


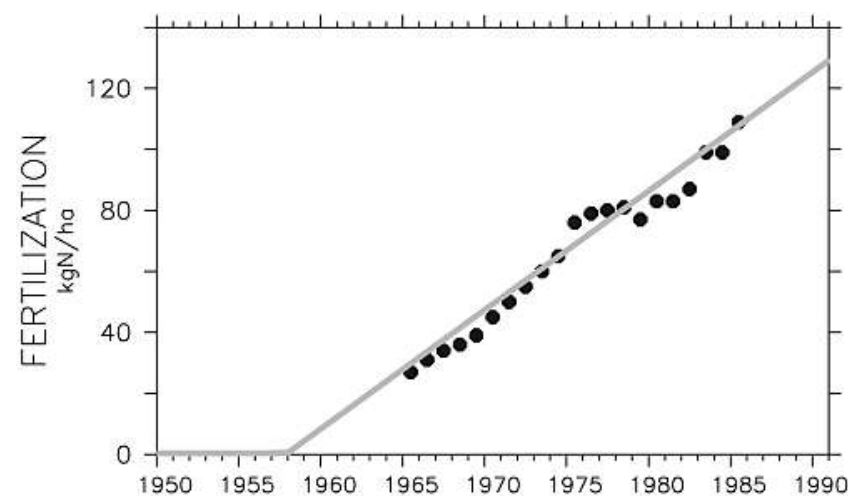

Figure 2. Amount of mineral $\mathrm{N}$ fertilizers used by former USSR agriculture. Dots are U.S. Department of Agriculture Statistics [1996] statistical data, and gray line is a linear extrapolation of these data used to drive the ORCHIDEESTICS crop model.

[Gervois et al., 2008, 2004; de Noblet-Ducoudré et al., 2004]. A short description of the two modules of ORCHIDEE is given in section 2.3. We first did a spin-up simulation with ORCHIDEE forced by cycling the meteorological conditions of year 1916. The spin up is stopped when all $\mathrm{C}$ pools have reached their equilibrium values. This spin-up is followed by a transient simulation between 1916 and 1950 where atmospheric $\mathrm{CO}_{2}$ and climate are varied at a $1^{\circ}$ by $1^{\circ}$ resolution [Mitchell et al., 2004]. Then, cultivation starts and the root biomass is immediately transferred to the soil (the aboveground biomass is almost zero). We assumed that all the cropland areas were established in 1951. This is obviously an oversimplification, however, not too unrealistic. Regional statistical data indicate a very sharp increase in the cultivated lands area in the $1950 \mathrm{~s}$, at a rate of $5.71 \mathrm{Mha} \mathrm{a}^{-1}$, due to the creation of new collective farms (kolkhoze), a process which started already in the 1930s but dramatically accelerated after the second world war [Houghton and Hackler, 2001], enhanced by the Soviet policy of agroindustrial integration.

[6] It is reasonable to assume that the arable land that was suddenly abandoned in the 1990 s concerned primarily the large-scale soviet kolkhozes, rather than the traditional small-scale collective farms and gardens. Thus, from 1951 to 1992 we have simulated cereals yields and NBP by using fertilization data representative of the large-scale former USSR collective farms [U.S. Department of Agriculture Statistics, 1996]. The extrapolation in time of these statistics led us to define that $\mathrm{N}$ fertilizer addition started at $3.75 \mathrm{~kg} \mathrm{~N}$ $\mathrm{ha}^{-1} \mathrm{a}^{-1}$ in 1958 and linearly increased up to $120 \mathrm{~kg} \mathrm{~N}$ $\mathrm{ha}^{-1} \mathrm{a}^{-1}$ in 1990 (Figure 2). For irrigation we let the model calculate the water required by crops. In ORCHIDEESTICS, a water stress is calculated at a daily time step. This stress varies from 1 (no stress) to $0(100 \%$ stress equals no growth). If the water stress gets below 0.8 , irrigation is activated for one day. The amount of water used is the minimum between a maximal value $(40 \mathrm{~mm})$ and the value for reaching the field capacity. During our simulation, over the grid cells where abandonment occurred, the mean amount of irrigation is $86 \mathrm{~mm} / \mathrm{a}$. This corresponds to $20 \%$ of the annual precipitation. Irrigation impacts positively on soil $\mathrm{C}$ stocks by increasing root litter. On the other hand, irrigation leads to higher soil moisture and consequently increases soil carbon decomposition. We considered that crop harvest removes all the grains and straws out of the field, thereby reducing $\mathrm{C}$ input to the soil down to roughly $30 \%$ of the crop NPP. We have also assumed that the tillage intensity, a practice for which no information was available, has accelerated litter and soil $\mathrm{C}$ decomposition by multiplying the residence time of all the soil $\mathrm{C}$ and litter pools in ORCHIDEE by an arbitrary factor of 0.7 .

[7] Between 1993 and 2000, we prescribed to ORCHIDEE successive yearly land cover maps (at a $1^{\circ}$ by $1^{\circ}$ resolution) reflecting the time dynamics of USSR cropland abandonment as defined by the Food and Agriculture Organization (FAO) statistics (Figure 1a) and Hurtt et al.'s [2006] spatial patterns described in section 2.1. Let $p_{y}$ be defined as the proportion of cultivated lands abandoned at year $y$ among all the lands abandoned during the 1990 s over a given grid point. The NBP of these lands abandoned at year y over the period 1991-2000 can be separated into two terms, one being related to the cultivated systems from 1991 to year $y\left(\mathrm{NBP}_{C, 1991-y}\right)$ and the other corresponding to the recovering grasslands $\left(\mathrm{NBP}_{G, y-2000}\right)$. The NBP over 1991-2000 of all the lands abandoned during the decade, $\mathrm{NBP}_{1991-2000}$, can be expressed as

$$
\mathrm{NBP}_{1991-2000}=\sum_{y=1991}^{2000} p_{y}\left(\mathrm{NBP}_{C, 1991-y}+\mathrm{NBP}_{G, y-2000}\right)
$$

According to the FAO statistics $p_{1991}$ and $p_{1992}$ are equal to zero, thus $N B P_{1991-2000}$ can thus be simplified into

$$
\mathrm{NBP}_{1991-2000}=\sum_{y=1993}^{2000} p_{y}\left(\mathrm{NBP}_{C, 1991-y}+\mathrm{NBP}_{G, y-2000}\right)
$$

The NBP of those grid points where no abandonment took place during the 1991-2000 period, remains equal to $N B P_{C, 1991-2000}$. Finally, the cumulated change in $\mathrm{C}$ during $1991-2000$ in response to agricultural abandonment is defined by

$$
C_{1991-2000}=\mathrm{NBP}_{C, 1991-2000}-\mathrm{NBP}_{1991-2000} .
$$

The assumptions that we made about Soviet agricultural technology are likely to impact the modeled $\mathrm{C}$ balance. Therefore, we have also investigated the sensitivity of the simulated NBP and $\mathrm{C}$ stocks to farming practice by performing a set of additional idealized sensitivity simulations with (1) no $\mathrm{N}$ fertilizer addition, (2) no tillage, and (3) an export of crop harvest residue leaving $10 \%$ of the straw on site available to the soil pools.

\subsection{Model Description and Improvements 2.3.1. Wheat Crop Modeling}

[8] ORCHIDEE is a process-based ecosystem model [Krinner et al., 2005] used for global and regional applications. The model calculates surface $\mathrm{CO}_{2}$, water vapor and 
heat fluxes driven by varying weather, and soil water and $\mathrm{C}$ pools dynamics. It contains a biophysical module dealing with photosynthesis and energy balance calculations each $30 \mathrm{~min}$, and a carbon dynamics module dealing with phenology, growth, allocation, mortality and SOM decomposition, on a daily time step. As in most global ecosystem models, the vegetation is described by using a distinct set of parameters for 13 different Plant Functional Types (PFT). Distinct PFTs follow the same set of governing equations, except for leaf onset and senescence, which involves a PFT specific parameterization [Botta et al., 2000]. As most of Global Vegetation Models, ORCHIDEE does not consider potential loss of carbon caused by wind and water erosion but it is not clear if erosion results in a net sink (redeposition) or a net source of carbon. The recent study of Van Oost et al. [2008] found a mean erosion rate by water and tillage of less than $10 \mathrm{gC} \mathrm{m}^{-2} \mathrm{a}^{-1}$ over Southern Russia and Ukraine, a flux five times smaller than the carbon accumulation or loss due to land use change.

[9] For better representing croplands in terms of physiology, phenology and management practices, ORCHIDEE is coupled to STICS, an agronomic model [Brisson et al., 2003, 1998]. STICS calculates crop phenology and biomass on a daily time step. It was originally developed and parameterized for cereals in France, dealing with irrigation, $\mathrm{N}$ fertilizer addition and harvest. In the coupled model [Gervois et al., 2004], STICS provides leaf area index (LAI) on a daily time step for ORCHIDEE to further calculate gross primary product (GPP) and NPP. The allocation scheme of ORCHIDEE has been adapted to remain consistent with the input daily LAI data. Yield is simply diagnosed from the "fruit" pool of ORCHIDEE. The ORCHIDEE-STICS model produces a rather realistic phenology and mean annual yield for winter wheat in Western Europe [Gervois et al., 2008, 2004], as shown by validation against agroecological site measurements of biomass and $\mathrm{CO}_{2}$ fluxes [Brisson et al., 2003; Gervois et al., 2004]. The model was also integrated over Western Europe for present-day conditions [de Noblet-Ducoudré et al., 2004; Gervois, 2004], and for the past century [Gervois et al., 2008] with changes in $\mathrm{CO}_{2}$, climate and agricultural technology. In these studies, the modeled wheat yield and its historical trends, averaged at the scale of countries, compares well with the FAO national statistics in temperate Europe, but overestimates the data in Mediterranean regions.

[10] In order to better simulate the allocation scheme for wheat, the C3 crop PFT in ORCHIDEE-STICS has been modified to reproduce the observed distribution of $\mathrm{C}$ between shoot and root biomass. We have used for that purpose the data compiled by Buyanovsky and Wagner [1986] for winter wheat in Missouri. They observed an allocation of the mean annual net annual production expressed in carbon mass of $33 \%, 47 \%$ and $20 \%$ for the roots, the straw and the grain pool respectively. We evaluated the crop model performance by comparing its simulated grain yields to agricultural yield statistics for wheat in the USSR between 1955 and 1989 [U.S. Department of Agriculture Statistics, 1996] in section 3.2.

\subsubsection{Grass-Dominated Vegetation Modeling}

[11] In order to better simulate grass-dominated ecosystems of the southern Russian and Central Asian regions, we improved the ORCHIDEE parameterization of phenology and photosynthesis, starting from generic equations and parameters of the natural C3 grass PFT. The model was modified in order to fit the eddy covariance measurements of an steppe eddy covariance site in the Hakassia region $\left(54.5^{\circ} \mathrm{N} 90.0^{\circ} \mathrm{E}\right.$ see Figure $\left.1 \mathrm{~b}\right)$ from July 2002 to December 2004 (see results in section 3.1). The site is situated at about 30 degrees $(\sim 2000 \mathrm{~km})$ to the east from the eastern boundary of the region of interest. However, it is in the steppe bioclimatic zone which is the major bioclimatic zone of the studied region. Annual mean temperature at the Hakassia site is $0.4^{\circ} \mathrm{C}$ while it is $8^{\circ} \mathrm{C}$ in our studied region (only grid cells where abandonment occurs). Annual precipitation equals $304 \mathrm{~mm}$ on the site and $578 \mathrm{~mm}$ within the region with some spatial heterogeneity. However, even if annual climate is different, the fact we use a generic model only driven by climate variables (no bioclimatic dependence of vegetation parameters) give us confidence in the results we obtain out of the validation site.

[12] The eddy covariance half-hourly NEE, latent and sensible heat fluxes are described by Belelli-Marchesini [2007] and Belelli-Marchesini et al. [2007]. NEE was separated into GPP and TER using the algorithm developed by Reichstein et al. [2005]. The LAI at this site was inferred from the SEAWIFFS FAPAR remote-sensing observation [Gobron et al., 2006] aggregated at spatial resolution of $6 \mathrm{~km}$, from the mean of 3 by 3 pixels at a $2 \mathrm{~km}$ resolution, each 10 days (http://fapar.jrc.it) and sampled at the flux tower location. LAI was deduced from FAPAR by inverting the equation FAPAR $=1-e^{\left(-k^{*} \mathrm{LAI}\right)}$ with $k=0.5$ [Monsi and Saeki, 1953].

[13] The step-by-step reparameterization of ORCHIDEE for steppes is described in details by Vuichard et al. (submitted manuscript, 2008). The following modifications were brought to the original model. First, the Vcmax and Vjmax photosynthesis rate constants have been fixed to 60 and $120 \mu \mathrm{mol} \mathrm{m} \mathrm{m}^{-2} \mathrm{~s}^{-1}$ respectively, that is values $25 \%$ smaller than in the original set of parameters. Second, the maximum LAI value was decreased by $50 \%$, down to $1.2 \mathrm{~m}^{2}$ $\mathrm{m}^{-2}$ to be brought into agreement with remote-sensing observation [Gobron et al., 2006]. Third, the allocation of GPP into soft tissues was decreased (new value of percent GPP allocated to soft tissues is 0.15). Fourth, we set up a maximum limit of 0.5 for the leaf allocation parameter (i.e., a 38\% reduction). Finally, the critical leaf age at which senescence begins was fixed to 60 days (50\% reduction) in order to accelerate the senescent decline of LAI, and the maximal leaf turnover time was shortened to 40 days $(50 \%$ reduction).

\subsection{Meteorological Drivers}

[14] The ORCHIDEE-STICS model is driven by $30 \mathrm{~min}$ values of air temperature, precipitation, specific humidity, wind speed, pressure, shortwave and longwave incoming radiation. These data, originally given as monthly fields at a resolution of $10^{\prime}$ by $10^{\prime}$ from the Climate Research Unit (CRU) data set of the University of East Anglia, UK 

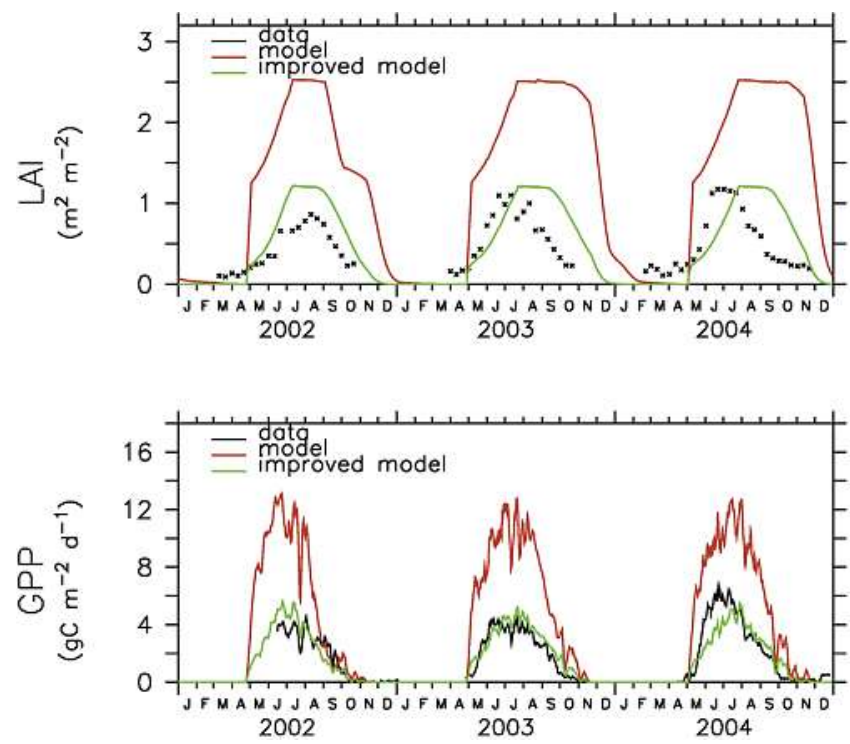

Figure 3. Evaluation of the ORCHIDEE model and of its improved version against LAI and eddy covariance GPP daily observations at a natural steppe site in southern Siberia.

[Mitchell et al., 2004], were aggregated to a $1^{\circ}$ by $1^{\circ}$ resolution. Half-hourly fields were prepared by adding to monthly mean CRU data the 6-hourly variability from the ERA-15 reanalysis data [Gibson et al., 1997]. Each variable was linearly interpolated between the 6-hourly data except for the radiation, which was interpolated with a cubic function taking its maximum value at noon and equal to zero between the sunset and the sunrise. Changes in atmospheric $\left(\mathrm{CO}_{2}\right)$ are also accounted for, with a rise from $\sim 300 \mathrm{ppm}$ for the early 20th century to $370 \mathrm{ppm}$ in 2000 .

\section{Results and Discussion}

\subsection{Model Evaluation for Natural Steppe}

[15] Results of the modified ORCHIDEE version in terms of GPP and LAI are shown on Figure 3. Overall, the modifications enable to better match the observed seasonal cycle of both LAI and GPP. Absolute values calculated by ORCHIDEE are also in better agreement with those observed. Model-data comparison for LAI leads to a regression slope of 0.91 and an intercept of $0.17 \mathrm{~m}^{2} \mathrm{~m}^{-2}$ with the modified model version (to compare with 1.60 and 0.71 for the slope and intercept of the original model version). For GPP, the regression slope obtained with the modified model is 0.85 and the intercept is $0.22 \mathrm{gC} \mathrm{m}^{-2} \mathrm{~d}^{-1}$ (Figure 3, to compare to 2.17 and 0.48 for the slope and intercept of the original version). Further, we found that improving GPP into ORCHIDEE immediately brings ecosystem respiration and net ecosystem exchange fluxes into better agreement with the eddy covariance data (auxiliary material). ${ }^{1}$

\footnotetext{
Auxiliary materials are available in the HTML. doi:10.1029 2008GB003212.
}

\subsection{Model Evaluation for Russian Wheat}

[16] The yield of wheat grain calculated by ORCHIDEESTICS matches well the agricultural statistics over the entire former USSR (Figure 4). The range of yield values as well as the general increasing trend and the interannual variability are well captured by the model, but there is a major limitation due to the fact that the statistics correspond to the whole agricultural area of USSR of 5.56 millions of $\mathrm{km}^{2}$ in 1990 [Food and Agriculture Organization, 2004] that is not all included in our model domain. From the comparison of the model runs with and without added mineral $\mathrm{N}$ fertilizers, we conclude that the increasing wheat yield trend is mainly due to fertilizer applications. Thus, surprisingly enough, our simple assumptions on the distribution of $\mathrm{N}$ fertilizer (section 2.2), based upon USSR average fertilizer use statistics, seems to be sufficient for reproducing the wheat grain yield increase over the 1955-1989 period. This suggests that wheat NPP in the more continental climate of the Russian plain is fairly realistic in ORCHIDEESTICS, although the model uses the parameters of a winter wheat variety grown in western Europe [Gervois, 2004]. However, model/data yield comparison leads to a $15 \%$ error over the $1955-1989$ period, and even to a $21 \%$ error over the 1985-1989 period. Because of the difficulty to relate the yield bias either to the NPP calculation, to the allocation scheme or to the $\mathrm{N}$ fertilizer data set we used, there is no possibility to know if this bias is also observed for the root biomass.

\subsection{Change in $\mathrm{C}$ Balance After Agricultural Abandonment}

\subsubsection{Natural Climate-Induced Variations}

[17] From 1993 to 2000, the mean annual NPP equals 584 and $207 \mathrm{gC} \mathrm{m}^{-2} \mathrm{a}^{-1}$ for wheat fields and grass-dominated ecosystems, respectively (Figure 5a). Part of the wheat NPP is exported away of the ecosystem as grains and straw. Thus, the fraction of NPP, which returns to the soil, is only $162 \mathrm{gC} \mathrm{m}^{-2}$. Interannual variability of NPP is poorly explained by fluctuations in the mean growing season air temperature (April-September) for both wheat fields and grass-dominated ecosystems (spatial mean $R 2$ of 0.11 and

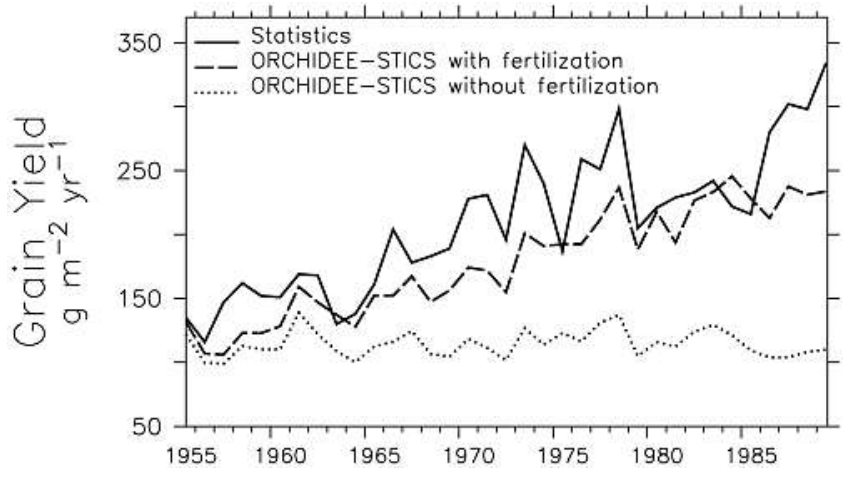

Figure 4. Evaluation of the modeled grain yields in Russian plain against U.S. Department of Agriculture Statistics [1996] statistical data representing an average for the whole USSR territory. 

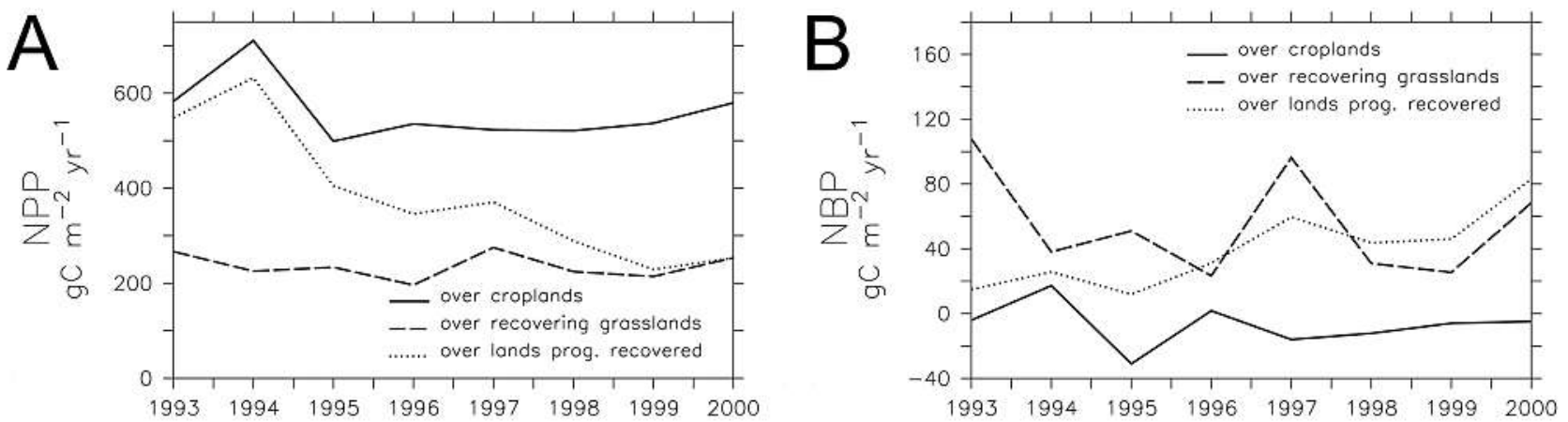

Figure 5. (a) Average net primary productivity and (b) average net biome productivity of Russian plain abandoned croplands. A $\mathrm{C}$ sink from the atmosphere is counted positively. Solid line corresponds to croplands, as if no abandonment had occurred. Dashed line is related to recovering grasslands, as if all the abandoned area throughout the 1990s was all suddenly abandoned in 1990. Dotted line is the most realistic case with a progressive abandonment of cropland areas throughout the 1990s from FAO statistics. The cumulated impact of cropland abandonment is the difference between the dotted and the solid line.

0.19 , respectively). Mean growing season precipitation is a slightly better predictor for the rainfed grass vegetation (spatial mean $R 2$ of 0.42 ).

\subsubsection{Temporal Dynamics of NBP Consecutive to Abandonment}

[18] In the absence of any land use change, the wheat fields are modeled to be a small source of carbon to the atmosphere $\left(\mathrm{NBP}_{C, 1991-2000}=-10 \mathrm{gC} \mathrm{m}^{-2} \mathrm{a}^{-1}\right.$, solid line in Figure $5 \mathrm{~b}$ ), even 40 years after cultivation. If we assume that all the arable lands cultivated with wheat are abandoned in 1993, the recovering grass-dominated vegetation is a large sink of carbon, with maximal sink intensity during the first year after abandonment $\left(\mathrm{NBP}_{G, 1993-2000}\right.$ varies between $105 \mathrm{gC} \mathrm{m}^{-2}$ and $20 \mathrm{gC} \mathrm{m}^{-2}$, dashed line in Figure 5b). The interannual variability of $\mathrm{NBP}_{G, 1993-2000}$ is higher $\left( \pm 33 \mathrm{gC} \mathrm{m}^{-2} \mathrm{a}^{-1}\right)$ than the one of $\mathrm{NBP}_{C, 1991-2000}$ ( $\pm 14 \mathrm{gC} \mathrm{m}^{-2} \mathrm{a}^{-1}$ ) for the following two reasons: (1) in our modeling framework, wheat fields can be irrigated, which dampens the variability because of rainfall variations, and
(2) on croplands, most of the NPP is exported out of the field, as grains or straw, limiting the impact of the NPP interannual variability on NBP.

[19] $\mathrm{NBP}_{1991-2000}$ is the yearly NBP of the progressively abandoned cultivated lands between 1991 and 2000 (Figure 1a). The temporal dynamics of $\mathrm{NBP}_{1991-2000}$ is shown by the dotted line on Figure $5 \mathrm{~b}$. NBP $1991-2000$ is a net C sink, which increases with time as the proportion of abandoned wheat fields increases. The annual change in $\mathrm{C}$ balance attributable to the abandonment of cultivated lands, $C_{1991-2000}$, corresponds to the difference between the dotted and the solid lines in Figure 5b. During the period 19912000 , the cumulated change in $\mathrm{C}$ storage, defined as $\Delta C=$ $\int C_{1991-2000}$, is $373 \mathrm{gC} \mathrm{m}^{-2}$ (spatial mean weighted by the percent of abandoned arable land in each grid point).

\subsubsection{Spatial Variations in NBP Consecutive to}

Abandonment

[20] The spatial distribution of $\Delta C$ is shown in Figure 6a. The highest values of $\Delta C$ (around $800 \mathrm{gC} \mathrm{m}^{-2}$ ) are
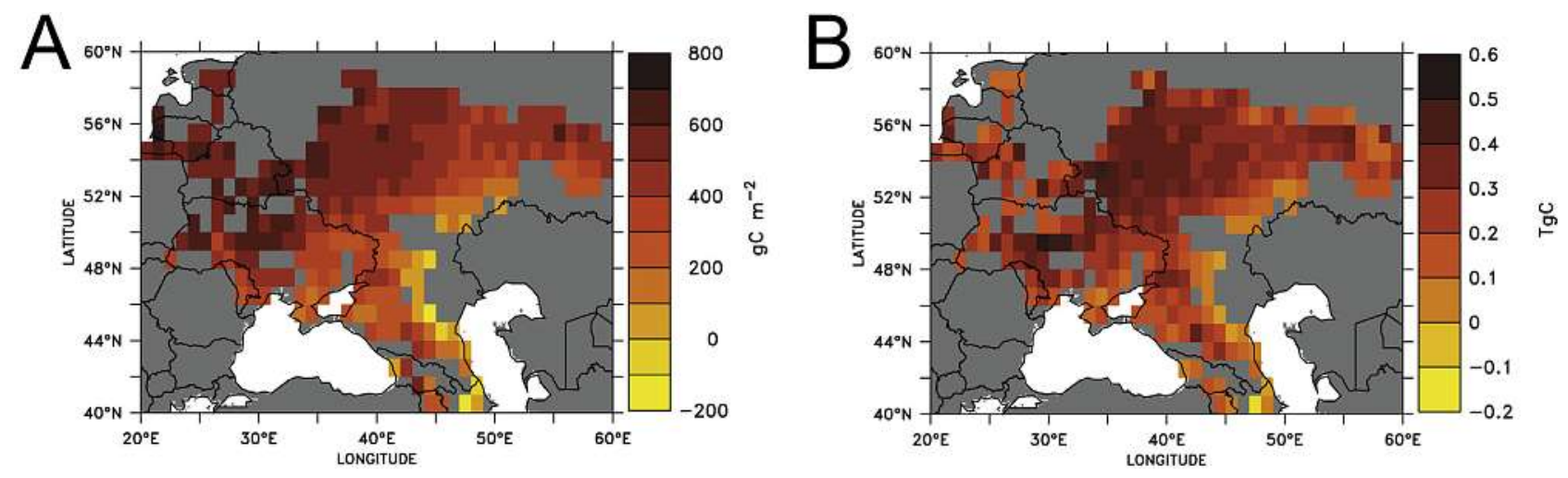

Figure 6. Spatial distribution of the cumulated carbon flux due to croplands abandonment during the 1990s expressed (a) per unit area (in $\mathrm{gC} \mathrm{m}^{-2}$ ) and (b) in absolute values ( $\mathrm{Tg} \mathrm{C}$ ) taking into account for the abandoned croplands area in each grid point. Positive values are gains and negatives ones are losses. 


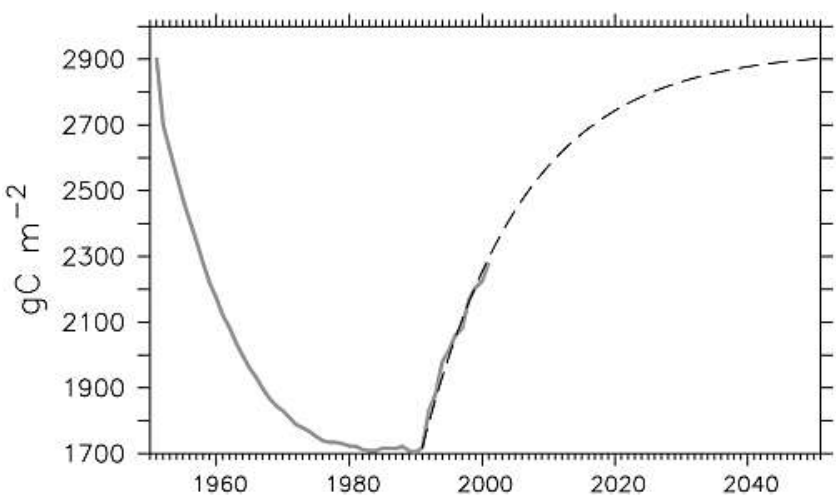

Figure 7. Soil $\mathrm{C}$ dynamic (in $\mathrm{gC} \mathrm{m}^{-2}$ ) as calculated by the ORCHIDEE-STICS model for a steppe primary land which experienced cultivation from 1950 to 1990 and an abrupt abandonment in 1991 and extrapolation by using a simple logistic curve for the time period 2000-2050.

obtained in the northwestern part of the region, and the lowest values in the southern part (around $-200 \mathrm{gC} \mathrm{m}^{-2}$ corresponding to a loss of carbon). This net loss of carbon in the southern part is explained by a decreasing trend of NPP over the grass ecosystem caused by a regional drying trend. Such a decreasing trend in the South is not impacting wheat, which is assumed to receive enough irrigation water for compensating its water stress. However, the NPP of grass ecosystem is at least a factor of 2 lower than the one of wheat (see Figure 5a), and even a factor of 6 lower in the southern part of the domain. Thus, the process that makes $\Delta C>0$ consecutive to abandonment is not a higher mean annual NPP, but rather the greater fraction of NPP which is returned to the soil in the recovering grass-dominated vegetation. In consequence, $\Delta C$ may be logically expressed as a function of the cumulated NPP of grass ecosystem $\left(\mathrm{NPP}_{G, \text { cum }}\right)$. We found that $\Delta \mathrm{C}$ reaches up to $70 \%$ of $\mathrm{NPP}_{G \text {,cum }}$ the first year after abandonment and progressively decreases to equal $30 \%$ of $\mathrm{NPP}_{G \text {,cum }} 8$ years after abandonment, as the depleted soil $\mathrm{C}$ pools replenish more and more slowly with time with new inputs. In terms of regional carbon balance, the NBP of abandoned wheat fields in the whole domain of Figure $1 \mathrm{~b}$ is a mean sink of $47 \mathrm{~g} \mathrm{C} \mathrm{m}^{-2}$ $\mathrm{a}^{-1}$ averaged over 1991-2000. This modeled NBP estimate is of the same order than the one reported by Post and Kwon [2000] (33.8 $\left.\mathrm{g} \mathrm{C} \mathrm{m}^{-2} \mathrm{a}^{-1}\right)$ in their literature survey.

\subsubsection{Implications for Regional $\mathrm{C}$ Balance}

[21] Multiplying the modeled NBP by the area of abandoned agriculture in each grid point (Figure 1b) defines a cumulated change in soil $\mathrm{C}$ storage ranging from -0.15 to up to $0.5 \mathrm{TgC}$ per grid point over the period 1991-2000 (Figure 6b). In the studied region, the abandonment of 17 Mha of arable land had led to a net cumulated gain of $64 \mathrm{Tg} \mathrm{C}$ over 1991-2000. According to this calculation, lands which have experienced abandonment have already recovered half of their 1950 soil $\mathrm{C}$ stock value during one decade after abandonment (Figure 7). By fitting a simple logistic curve to our modeled curve of soil $\mathrm{C}$ storage dynamics, we estimate that these lands will need 50 more years for fully recovering their initial 1950 stock value
(Figure 7). This leads us to expect that the massive land use reversal from arable land to grass-dominated ecosystem which followed the collapse of Soviet Agriculture will be responsible of a sink of $70 \mathrm{Tg} \mathrm{C}$ in the next five decades.

\subsection{Sensitivity of $\mathrm{C}$ Balance to Wheat Management Practice}

[22] In this section, the control model experiment is the one described above. In a sensitivity experiment (section 2.2) without $\mathrm{N}$ fertilizer addition during the cultivation period 1951-1990, the modeled wheat NPP decreases by $\sim 30 \%$. In consequence, the carbon stocks in 1990 are $20 \%$ lower than with $\mathrm{N}$ fertilizers. As a consequence, the $\mathrm{C}$ gain resulting from the rebound of cultivation abandonment would be higher than in the control by $37 \%$ in the case of no former $\mathrm{N}$ fertilizer application $(87 \mathrm{TgC}$ over 1991-2000). However, in the control experiment, we did not account for the carry-over effects of residual fertilizerbound $\mathrm{N}$ in enhancing the NPP of grass ecosystem after abandonment. In such N-limited systems, one would therefore expect a NPP and $\Delta \mathrm{C}$ to be greater than actually calculated in section 3.3. These carryover effects of former $\mathrm{N}$ fertilizers could be modeled in the future with the new version ORCHIDEE-STICS-carbon-nitrogen cycle (CN), which includes nitrogen cycling (S. Zaehle and A. D. Friend, Carbon-nitrogen cycle dynamics in the ORCHIDEE-CN land surface model: Part 1: Model evaluation and sensitivity, manuscript in preparation, 2008). In the sensitivity experiment (section 2.2) where no-tillage practice is assumed, the cropland soil C stock in 1990 is $25 \%$ higher than in the control, which in turn determines a $25 \%$ lower value of $\Delta \mathrm{C}$ (48 Tg C). Finally, the sensitivity experiment where it is assumed that $10 \%$ of crop harvest residues are left in the field leads to a $15 \%$ lower value of $\Delta \mathrm{C}$ than in the control (54 $\mathrm{Tg} \mathrm{C})$. We did not investigate regionally the impact of irrigating the croplands on the $\mathrm{C}$ gain. However, simulations on representative grid points show that irrigation during the cultivation period leads to a decrease of soil $\mathrm{C}$ stocks because the negative impact of increasing soil moisture on soil $\mathrm{C}$ stocks is higher than the positive one of increasing root litter. In consequence, to consider rain-fed crops would have probably reduced the $\mathrm{C}$ gain by 5 to $10 \%$.

\section{Conclusion}

[23] The simulations presented here indicate that the massive abandonment of croplands in the former USSR in the 1990s has induced a net $\mathrm{C}$ sequestration rate of $47 \mathrm{gC}$ $\mathrm{m}^{-2} \mathrm{a}^{-1}$. It is roughly $50 \%$ higher than the observed $\mathrm{C}$ sequestration rates in the Russian forests for 1961-1998 ( $\sim 31 \mathrm{gC} \mathrm{m}^{-2} \mathrm{a}^{-1}$ [Shvidenko and Nilsson, 2003]). Thus, this land use induced net $\mathrm{C}$ sequestration rate is significant and leads to a net $\mathrm{C}$ sink (NBP) of $64 \mathrm{Tg}$ over $171,000 \mathrm{~km}^{2}$ during the period 1993-2000. However, at the regional scale this sink does not contribute significantly to the carbon balance mainly because the area of the abandoned cultivated lands of former USSR is small $\left(\sim 0.210^{6} \mathrm{~km}^{2}\right)$ in comparison for instance of the lands of the Russian forests $(\sim 8.8$ $10^{6} \mathrm{~km}^{2}$ ). Estimates of the carbon sink of the Russian 
forests are $268 \mathrm{Tg} \mathrm{C}^{-1}$ and $272 \mathrm{Tg} \mathrm{C}^{-1}$ by pool- and flux-based methods respectively [Shvidenko and Nilsson, 2003] while the carbon sink over the abandoned cultivated lands of the former USSR is $8 \mathrm{Tg} \mathrm{C} \mathrm{a}^{-1}$. However, the focus should be more on the change in the $\mathrm{C}$ balance rather than its absolute value. In this respect, the contribution of the studied land conversion to the regional $\mathrm{C}$ balance change over the 1990 s is certainly significant.

[24] The main controlling process of NBP in our case study is the large fraction of grass NPP which gets returned to the soil, against only a small fraction of NPP in croplands. This larger return to the soil compensates for the lower NPP of grass ecosystem compared to croplands. Therefore, not surprisingly, our modeled net change in soil $\mathrm{C}$ stock is quite sensitive to the agricultural practice applied during the period of cultivation: tillage/fate of straw residues/ $\mathrm{N}$ fertilizers. According to a set of model sensitivity experiments where each of these practice are turned off, it is the input of $\mathrm{N}$ fertilizers which impacts the most the simulated change in soil $\mathrm{C}$ storage after abandonment $(+37 \%)$. However, in this sensitivity study, we only considered the impact on soil $\mathrm{C}$ storage of management practices taken one by one. Combining different practices should lead to a higher range of uncertainty. For instance, considering both reduced export of straw and no tillage should decrease the $\mathrm{C}$ gain after abandonment by up to $40 \%$. Therefore, we strongly recommend that future studies should better represent management information in order to improve the NBP estimate. It will be also interesting to compare for future scenarios, how $\mathrm{C}$ gains legated from the agricultural abandonment might be offset by $\mathrm{C}$ losses implied by soil warming and faster decomposition.

[25] Acknowledgments. We acknowledge the University of New Hampshire, EOS-WEBSTER Earth Science Information Partner (ESIP), as the data distributor for the Global Land use Modeling data set and the Joint Research Center, Institute for Environment and Sustainability, as the data distributor for the FAPAR data set. We also thank two anonymous reviewers for comments that improved this manuscript. This study was funded in part by the CARBOEUROPE-IP European project GOCE-CT$2003-505572$

\section{References}

Belelli-Marchesini, L. (2007), Analysis of the carbon cycle of steppe and old field ecosystems of central Asia, Ph.D. thesis, 209 pp., Univ. of Tuscia, Viterbo, Italy.

Belelli-Marchesini, L., et al. (2007), Carbon balance assessment of a natural steppe of southern Siberia by multiple constraint approach, Biogeosciences, 4, 581-595.

Botta, A., et al. (2000), A global prognostic scheme of leaf onset using satellite data, Global Change Biol., 6, 709-725, doi:10.1046/j.13652486.2000.00362.x.

Brisson, N., et al. (1998), STICS a generic model for the simulation of crops and their water and nitrogen balances. Part I. Theory and parameterization applied to wheat and maize, Agronomie, 18, 311-346, doi:10.1051/agro:19980501.

Brisson, N., et al. (2003), An overview of the crop model STICS, Eur. J. Agron., 18, 309-332, doi:10.1016/S1161-0301(02)00110-7.

Buyanovsky, G. A., and G. H. Wagner (1986), Post-harvest residue input to cropland, Plant Soil, 93, 57-65, doi:10.1007/BF02377145.

de Noblet-Ducoudré, N., et al. (2004), Coupling the soil-vegetationatmosphere-transfer scheme ORCHIDEE to the agronomy model STICS to study the influence of croplands on the European carbon and water budgets, Agronomie, 24, 397-407, doi:10.1051/agro:2004038.

Food and Agriculture Organization (2004), FAOSTAT Data, http://faostat. fao.org, Food and Agric. Organ., New York.
Feddema, J. J., et al. (2005), The importance of land cover change in simulating future climates, Science, 310, 1674-1678, doi:10.1126/ science. 1118160 .

Gervois, S. (2004), Les zones agricoles en Europe: Évaluation de leur rôle sur les bilans d'eau et de carbone à l'échelle de l'Europe; sensibilité de ces bilans aux changements environnementaux sur le vingtième siècle, $\mathrm{Ph} . \mathrm{D}$. thesis, 252 pp., Univ. Pierre et Marie Curie, Paris.

Gervois, S., et al. (2004), Including croplands in a global biosphere model: Methodology and evaluation at specific sites, Earth Interact., 8, 1-25, doi:10.1175/1087-3562(2004)8<1:ICIAGB $>2.0$. CO;2.

Gervois, S., P. Ciais, N. de Noblet-Ducoudré, N. Brisson, N. Vuichard, and N. Viovy (2008), Carbon and water balance of European croplands throughout the 20th century, Global Biogeochem. Cycles, 22, GB2022, doi: $10.1029 / 2007 \mathrm{~GB} 003018$.

Gibson, J. K., P. Kallberg, S. Uppala, A. Hernandez, A. Nomura, and E. Serrano (1997), ERA description, ERA-15 Proj. Rep. Ser. 1, Eur. Cent. for Medium-Range Weather Forecasts, Reading, UK.

Gobron, N., et al. (2006), Evaluation of fraction of absorbed photosynthetically active radiation products for different canopy radiation transfer regimes: Methodology and results using Joint Research Center products derived from SeaWiFS against ground-based estimations, J. Geophys. Res., 111, D13110, doi:10.1029/2005JD006511.

Houghton, R. A., and J. L. Hackler (2001), Carbon Flux to the Atmosphere From Land use Changes: 1850 to 1990, http://cdiac.ornl.gov/epubs/ndp/ ndp050/ndp050.html, Carbon Dioxide Inf. Anal. Cent., Oak Ridge Natl. Lab., Oak Ridge, Tenn.

Hurtt, G. C., et al. (2006), The underpinnings of land use history: Three centuries of global gridded land use transitions, wood-harvest activity, and resulting secondary lands, Global Change Biol., 12, 1208-1229, doi:10.1111/j.1365-2486.2006.01150.x.

Krinner, G., N. Viovy, N. de Noblet-Ducoudré, J. Ogée, J. Polcher, P. Friedlingstein, P. Ciais, S. Sitch, and I. C. Prentice (2005), A dynamic global vegetation model for studies of the coupled atmosphere-biosphere system, Global Biogeochem. Cycles, 19, GB1015, doi:10.1029/ 2003GB002199.

Mitchell, T. D., et al. (2004), A comprehensive set of high resolution grids of monthly climate for Europe and the globe: The observed record (1901-2000) and 16 scenarios (2001-2100), Tyndall Cent. Working Pap. 55, Tyndall Cent., Norwich, UK.

Monsi, M., and T. Saeki (1953), Über den Lichtfactor in der Pflanzengesell schaffen und seine bedeutung für die stoffproduktion, Jpn. J. Bot., 14, $22-52$.

Pielke, R. A., Sr. (2005), Land use and climate change, Science, 310, 1625-1626, doi:10.1126/science.1120529.

Post, W. M., and K. C. Kwon (2000), Soil carbon sequestration and land use change: Processes and potential, Global Change Biol., 6(3), $317-$ 327, doi:10.1046/j.1365-2486.2000.00308.x.

Reichstein, M., et al. (2005), On the separation of net ecosystem exchange into assimilation and ecosystem respiration: Review and improved algorithm, Global Change Biol., 11(9), 1424-1439, doi:10.1111/j.13652486.2005.001002.x.

Shvidenko, A., and S. Nilsson (2003), A synthesis of the impact of Russian forests on the global carbon budget for 1961-1998, Tellus, 55B(2), 391415 .

Smith, J. U., et al. (2005), Projected changes in mineral soil carbon of European croplands and grasslands, 1990-2080, Global Change Biol., 11, 2141-2152, doi:10.1111/j.1365-2486.2005.001075.x.

U.S. Department of Agriculture Statistics (1996), USSR: Grain Area, Yield and Production by Republic and Grain Type, 1955-1989, http:// gcmd.nasa.gov/records/GCMD USDA0034.html, U.S. Dep. Of Agric., Washington, D. C.

Van Oost, K., et al. (2008), The impact of agricultural soil erosion on the global carbon cycle, Science, 318(5850), 626-629, doi:10.1126 science. 1145724 .

L. Belelli and R. Valentini, Department of Forest Resources and Environment, University of Tuscia, Via San Camillo de Lellis, I-01100 Viterbo, Italy.

P. Ciais and P. Smith, Laboratoire des Sciences du Climat et de l'Environnement, IPSL, CEA, CNRS, Gif-sur-Yvette F-91191, France.

N. Vuichard, Centre International de Recherche sur l'Environnement et le Développement, EHESS, CNRS, 45bis Avenue de la Belle Gabrielle, F94736 Nogent sur Marne, France. (vuichard@gmail.com) 